\title{
VIERING VAN 50 JAAR VLAAMSE TELEVISIE IN BELGIË DOOR DE VLAAMSE OPENBARE OMROEP VRT: ENTERTAINEND EN CANONISEREND
}

De viering van een halve eeuw televisie is momenteel in vele West-Europese landen aan de orde. Naast Nederland, dat in I95I met televisie-uitzendingen van start ging, herdachten ook Duitsland, Engeland en Frankrijk, die alledrie reeds voor de tweede wereldoorlog met uitzendingen experimenteerden, de nationale introductie van het televisiemedium. Met zijn officieel begin op 3I oktober I953 staat België, waar het televisie-initiatief door de openbare (radio-)omroep werd genomen, als vijfde in de rij.

Als voorloper en voorafspiegeling van de federalisering van België werd de openbare omroep vanaf zijn ontstaan in I930, rekening houdend met de twee grootste bevolkingsgroepen, onderverdeeld in een Vlaamse Openbare Omroep NIR/BRTBRTN/VRT (Nederlands) en een Waalse Openbare Omroep INR/RTB/ RTBF (Frans). ${ }^{2}$ In 2003-2004 vierden beide omroepen vijftig jaar televisie vrij autonoom en onafhankelijk van elkaar, op delen van de openings- en slotshow en het gemeenschappelijke logo na. De verschillende aanpakken van beide zenders leidden tot een totaal andere output van herdenkingsprogramma's. Of deze verschillen ruimer model staan voor diverse opvattingen over televisie binnen WestEuropa kan in dit stadium nog niet worden bepaald. Een vergelijkende analyse van de herdenkingen naar aanleiding van vijftig jaar televisie bij andere WestEuropese omroepen zou in deze context boeiende inzichten kunnen bieden.

De Vlaamse openbare omroep (VRT) vierde zijn verjaardag tussen oktober 2003 en september 2004 en zond onder de vlag '50 jaar TV' allerlei feestprogramma's uit. In het kader van het feestjaar creëerden verschillende productieeenheden afzonderlijke programma's en/of integreerden ze de verjaardagshappening in hun bestaande programma-aanbod. Een overzicht van het totaalaanbod van programma's en programmareeksen in het teken van vijftig jaar televisie is opgenomen in het volgende overzicht. 
Classificatie van de programma's en programmareeksen naar aanleiding van de 50 e verjaardag van televisie op de Vlaams Openbare omroep (2003-2004) ${ }^{3}$

\begin{tabular}{|c|c|c|c|}
\hline Entertainment & Infotainment & Debat a studiogesprek & Informatie Q documentaires \\
\hline $\begin{array}{l}\text { - Show } \\
\text { ALLES VOOR DE SHOW } \\
\text { ZAP! } \\
\text { FICTIEFREAK } \\
\text { - Heruitzendingen van } \\
\text { fictieprogramma's (eigen } \\
\text { oude producties; } \\
\text { aangekochte producties en } \\
\text { recente producties) } \\
\text { WIJ, HEREN VAN ZICHEM } \\
\text { PARADIJSVOGELS } \\
\text { DE KOLDERBRIGADE } \\
\text { MARIA SPEERMALIE } \\
\text { HARD LABEUR } \\
\text { DE COLLEGA'S } \\
\text { LANGS DE KADE } \\
\text { JEROOM EN BENZAMIEN } \\
\text { ALFA PAPA TANGO } \\
\text { MET VOORBEDACHTEN } \\
\text { RADE } \\
\text { UPSTAIRS-DOWNSTAIRS } \\
\text { BONANZA } \\
\text { SECRET ARMY } \\
\text { - Heruitzendingen van } \\
\text { jeUgdSeries } \\
\text { KAPITEIN ZEPPOS } \\
\text { JOHAN EN DE ALVERMAN } \\
\text { DE KAT }\end{array}$ & $\begin{array}{l}\text { - Quiz } \\
\text { PER SECONDE WIJZER } \\
\text { - Sport } \\
\text { (archiefmateriaal) } \\
\text { DAAR IS 'M } \\
\text { NIET TE WISSEN } \\
\text { - Muziekgeschiedenis } \\
\text { DE PRE-HISTORIE } \\
\text { - Over media happenings } \\
\text { DE RODE LOPER } \\
\text { - Hoe televisie werd/wordt } \\
\text { gemaakt } \\
\text { WITTE RAVEN }\end{array}$ & $\begin{array}{l}\text { - Met eigen en } \\
\text { buitenlandse } \\
\text { televisiepersoonlijkheden } \\
\text { TV.GASTEN } \\
\text { SPRAAKMAKERS } \\
\text { - Over de impact van } \\
\text { televisie op de } \\
\text { samenleving } \\
\text { NACHTWACHT }\end{array}$ & $\begin{array}{l}\text { DAT WAS HET NIEUWS } \\
\text { NIEUWSMAKERS } \\
\text { - Panorama geschiedenis } \\
\text { PANORAMA } 50 \\
\text { - Human interest } \\
\text { historische programma's } \\
\text { EN NU? } \\
\text { - Retrospectieve bij } \\
\text { overleden televisie- } \\
\text { persoonlijkheden } \\
\text { DOE HET LICHT MAAR } \\
\text { AAN } \\
\text { - Historische Vlaamse } \\
\text { televisie } \\
\text { HISTORIES } \\
\text { - Over archivering van } \\
\text { beeldmateriaal } \\
\text { OVERLEVEN } \\
\text { - Heruitzending beste } \\
\text { documentaires } \\
\text { GRAND CRU }\end{array}$ \\
\hline 480 uitzendingen & Ioo uitzendingen & $\sim 20$ uitzendingen & $\begin{array}{l}\text { } 35 \text { uitzendingen } \\
\text { + dagelijks heruitzending } \\
\text { van een vroeger nieuws- } \\
\text { item: DAT WAS HET } \\
\text { NIEUWS }\end{array}$ \\
\hline $\begin{array}{l}\text { 75,6\% van alle feest- } \\
\text { programma's }\end{array}$ & \multicolumn{3}{|c|}{$\sim 24,4 \%$ van alle feestprogramma's } \\
\hline $\begin{array}{l}\text { Io० uitzendingen in } \\
\text { prime time (= 2I\% van } \\
\text { gelegenheidsentertainment } \\
\text { aanbod) }\end{array}$ & $\begin{array}{l}\text { 80 uitzendingen in } \\
\text { prime time (= 80\% van } \\
\text { gelegenheidsinfotainment } \\
\text { aanbod) }\end{array}$ & $\begin{array}{l}\text { Io uitzendingen in } \\
\text { prime time (= 50\% van } \\
\text { gelegenheidsdebatten \& } \\
\text { gesprekken) }\end{array}$ & $\begin{array}{l}\text { I5 uitzendingen in pri- } \\
\text { me time (= } 43 \% \text { van gele- } \\
\text { genheidsuitzendingen in- } \\
\text { formatie \& documentaires) } \\
\text { + dagelijks heruitzending } \\
\text { van een vroeger nieuws- } \\
\text { item: DAT WAS H ET } \\
\text { NIEUWS }\end{array}$ \\
\hline
\end{tabular}


Over het aandeel van dit soort programma's in het totale vRT-zendurenaanbod zijn momenteel nog geen exacte cijfers bekend. ${ }^{4}$ Een ruwe berekening van eigen datagegevens en rekening houdend met het totale aantal zenduren in 2002 (= 825 I uren) en in 2003 ( $=8254$ uren $)^{5}$ resulteert in een aandeel van vermoedelijk 7 à I0\%.

Dit artikel biedt een bondig overzicht van de feesthappening en wil deze aan een eerste kritische blik onderwerpen. Hiertoe worden de diverse gelegenheidsprogramma's naar aard van het programma ingedeeld. De klemtoon valt hierbij duidelijk op entertainment, met een bijzondere aandacht voor heruitzendingen van eigen fictiereeksen en jeugdseries. In een tweede stap worden enkele terugkerende kenmerken in de werkwijze voor de samenstelling van deze feestprogramma's aangetoond. Basisingrediënten waren: persoonlijke herinneringen van producers, gecanoniseerde verhalen over de omroep en getuigenissen van betrokkenen. Deze geven aanleiding tot een specifieke en eigen reconstructie van het televisieverleden. Ten derde wordt het succes bij het publiek onderzocht. Deze globale analyse is geplaatst in een breder socio-cultureel en historisch kader waarbij de Vlaamse televisie een rol als entertainer en een rol in een Vlaamse identiteitsconstructie vervult.

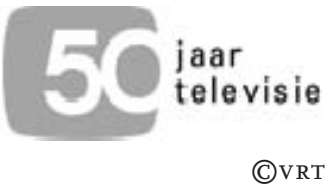

\section{Entertainment als hoofdmenu}

De door de VRT aangeboden feestuitzendingen (zie tabel) zijn in deze analyse in vier categorieën ${ }^{6}$ onderverdeeld: entertainment, infotainment, debatten \& studiogesprekken en tot slot informatie \& documentaire programma's. Het entertainmentaanbod bevat vooral showprogramma's en heruitzendingen van fictie- en jeugdseries: een mix van eigen, aangekochte, oude en recente reeksen. Enkele toppers uit de eigen producties waren wiJ, HEREN VAN ZICHEM (I969), ? DE COLlEGA's (I978), PARADIJSVOGELS (I979), LANGS DE KADE (I988) en de jeugdseries KAPITEIN ZEPPOS (I964, I968) en JOHAN EN DE ALVERMAN (I965). UPSTAIRS-DOWNSTAIRS En BONANZA behoren tot de succesrijke buitenlandse producties. De infotainmentgroep bestaat uit quizprogramma's zoals PER SECONDE WIJZER, sportuitzendingen (DAAR IS 'M En NIET TE WISSEN), reportages over mediahappenings in DE RODE LOPER, muziekgeschiedenis in DE PREHISTORIE en realitytelevisie over hoe een televisieprogramma tot stand komt (WITTE RAVEN). De debatten \& studiogesprekken hebben vooral betrekking op ontmoetingen met televisiepersoonlijkheden. Slechts één debat in NACHT- 
WACHT handelt over de invloed van televisie op de samenleving. De categorie informatie \& documentaires vertegenwoordigt historische reportages over de ontwikkeling van televisie (HISTORIES REEKS, DOE HET LICHT MAAR AAN) en in het bijzonder van haar eigen informatieprogramma's (zoals NIEUWSMAKERS, PANORAMA 5O, EN NU?). Afzonderlijke aandacht ging uit naar de problemen omtrent archivering (OVERLEVEN).

Het overwicht van het entertainmentaanbod is ontegensprekelijk. Omgerekend naar het aantal uitzendingen ${ }^{8}$ behoort 75,6\% van alle gelegenheidsprogramma's tot de entertainmentcategorie. Binnen deze entertainmentrubriek beslaat het aandeel van de heruitzendingen van fictiereeksen en jeugdseries $90 \%$. Een analyse van de prime time-uitzendingen ${ }^{9}$ toont aan dat $80 \%$ van de infotainmentprogramma's, 50\% van de debatten \& studiogesprekken, $43 \%$ van de gelegenheidsinformatie \& documentaires en slechts $2 \mathrm{I} \%$ van het entertainmentaanbod op prime time werden uitgezonden. Entertainment stond vooral op namiddagen en niet op prime time geprogrammeerd. Toch resulteerde het in een kijkcijfersucces. Dit valt te verklaren uit de intrinsieke kracht van de aard van de heruitgezonden programma's (waarop verderop wordt teruggekomen). Maar eveneens omdat vooral oudere en bejaarde mensen deel uitmaken van het doelpubliek, voor wie deze series jeugdherinneringen oproepen.

\section{Canonisering van de eigen televisiegeschiedenis}

De samenstelling van de meeste gelegenheidsprogramma's veronderstelde een historische terugblik. Op basis van diverse gesprekken, eigen onderzoek, de feitelijke uitzendingen en persberichten blijkt duidelijk dat persoonlijke herinneringen van producers, gecanoniseerde verhalen over de omroep en getuigenissen van betrokken televisiepioniers cruciaal waren voor deze reconstructies. Het gemis aan (encyclopedisch) historische referentiewerken over de Vlaamse televisie alsook de concrete toestand van de niet ontsloten beeld- en documentenarchieven stimuleerden deze werkwijze. Hierdoor streefde de omroep met zijn gelegenheidsprogramma's niet naar een genuanceerd en evenwichtig historisch correct overzicht. In plaats daarvan bracht men bepaalde producties, gebeurtenissen en personen terug in beeld. Dit geeft aanleiding tot een canoniseren van de eigen omroepgeschiedenis, duidelijk gestuurd vanuit de blik van televisiemakers nu en vroeger.

Ten eerste is er het belangrijke aandeel van de heruitzendingen van fictie en jeugdseries, die samen 68,8\% van het totale feestaanbod uitmaken. Deze heruitzendingen bestaan voor tweederde uit eigen materiaal. De wetenschappelijke studie over deze Vlaamse fictieseries van Alexander Dhoest $(2004)^{\text {IO }}$ toont aan dat de beelden, voorstellingen en verhalen in dit aanbod mede het discours omtrent een Vlaamse identiteit construeerden en voedden. De meeste van deze programma's waren in het verleden heel succesrijk bij het Vlaamse publiek. 
Door juist deze reeksen terug op het scherm te brengen, versterkt men een collectieve herinnering. Dit leidt tot een canonisering van deze specifieke programma's maar ook van de historisch maatschappelijke rol van de Vlaamse televisie in een Vlaamse identiteitsconstructie. Door deze keuze legitimeert de Vlaamse televisie haar bestaan opnieuw op basis van een niet steeds uitgesproken Vlaamse missie. De heruitzending van een vroeger nieuwsitem op het einde van het journaal ligt volledig in het verlengde van deze strategie. Men kon namelijk alleen die nieuwsitems selecteren waarop de omroep de rechten bezit. Dit zijn bijna uitsluitend de berichten die door eigen cameramensen en journalisten werden gerealiseerd. Dit betekent concreet dat deze items voor meer dan 90\% opnames en gebeurtenissen in Vlaanderen weergeven. In die zin droeg de feestrubriek DIT WAS HET NIEUWs fragmentarisch duidelijk bij tot een constructie van een Vlaamse geschiedenis.

Voor de productie van de overige 31,2\% gelegenheidsprogramma's rustte het basisconcept meestal op persoonlijke herinneringen. In bijna $20 \%$ van deze programma's werd archiefmateriaal verwerkt. Eigen medewerkers werden geengageerd om contacten te leggen met televisiepioniers en opzoekwerk te verrichten. Dit leidde tot een verzameling van weetjes, feiten, anekdoten, verhalen en getuigenissen die handig werd geïntegreerd in moderne formats, wat resulteerde in geslaagde en succesrijke televisieprogramma's. Hiermee bewijzen de huidige televisiemakers hun deskundigheid in het werken met het medium televisie.

\section{Succes bij het publiek}

Op basis van de kijkcijfers kan de aanpak van de viering van vijftig jaar televisie terecht een succes genoemd worden. De openingsshow op 3I oktober 2003 haalde meer dan één en een kwart miljoen kijkers. Deze uitzending staat trouwens op basis van de kijkcijfers in de Top Ioo van alle televisieprogramma's in Nederlandstalig België (2003) op de vijftiende plaats gerangschikt. II De heruitzendingen van fictiereeksen en jeugdseries - dikwijls op namiddagen geprogrammeerd - werden massaal gevolgd, met een piek tot bijna vierhonderdduizend kijkers voor de heruitzendingen van de jeugdseries JO HAN EN DE ALVERMAN en KAPITEIN ZEPPOS. ${ }^{\text {I2 }}$ Bij de ouderen zijn ze onlosmakelijk verbonden met eigen jeugdherinneringen en bij het jonge publiek wekken ze nieuwsgierigheid op. Het succes ligt echter niet enkel in de persoonlijke herinnering. Deze programma's worden gekenmerkt door een heel specifiek Vlaams discours. De waardering voor deze heruitzendingen ligt dus mede in de intrinsieke kracht van een collectief gedeelde en doorgegeven herinnering. Ze zijn een exponent van een reeds gecanoniseerde omroepgeschiedenis alsook van een gecanoniseerd deel Vlaamse geschiedenis. Beide worden opnieuw bekrachtigd. Ook de verkoop van de DVD'S 50 JAAR TELEVISIE waarop sommige van deze programma's gebun- 
deld werden, bevestigt dit fenomeen. Deze verkoop verliep in hoofdzaak via een actie met de krant Het Nieuwsblad die honderdvijftigduizend exemplaren bestelde en die er meer dan honderdduizend effectief aan de man bracht. ${ }^{\mathrm{I}}$ De heruitzending van een vroeger nieuwsitem op het einde van het journaal mocht op waardering rekenen. Daartegenover viel de DVD-verkoop van DIT WAS HET NIEUWs met slechts een 630 exemplaren grondig tegen. ${ }^{\text {I4 }}$

Ook de andere programma's mochten op grote bijval rekenen, zeker bij de start van het feestjaar. ${ }^{15}$ Hiermee wordt het huidige televisieconcept bevestigd. Televisie brengt een mix van entertainment, infotainment, debatten en gesprekken en informatie en documentaires. De gemaakte analyse toont aan dat het aangename en ontspannende element voor de televisiekijker wel degelijk telt.

Meer dan entertainen?

Was het feestaanbod van de Vlaamse openbare omroep een middel om te entertainen? Deze vraag verdient een bevestigend antwoord. De Vlaamse televisie slaagde erin om met de huidige middelen een geheel te brengen dat aansloeg bij het publiek. In hoofdzaak ontspannend en entertainend, doorspekt met weetjes en informatie. Tegelijk toont deze analyse aan dat de concrete praktijk echter ook leidt tot een constructie van een eigen televisiegeschiedenis en een collectief gedeelde herinnering. Opmerkelijk hierbij is hoe persoonlijke herinneringen van producers en televisiepersoonlijkheden van vroeger en nu in deze producties uitgroeien tot een collectieve gedeelde geschiedenis. Het heruitzenden van stukken archiefmateriaal voedt deze collectieve herinneringen met welbepaalde beelden. Deze fragmentarisch opgebouwde geschiedenis dwingt tot het besef dat bepaalde elementen extra belicht worden en andere (voorgoed?) verdwijnen in de mist van de geschiedenis. Door de viering van vijftig jaar televisie vertelt, maakt, schrijft en herschrijft de Vlaamse televisie haar eigen geschiedenis, alsook een gedeeld populair collectief verleden.

Noten

I UNESCO, 'Statistiques de la radiodiffusion et de la télévision I950-1960', I962, p. 75-76.

2 Voor een gedetailleerder overzicht omtrent het ontstaan van de Vlaamse openbare televisieomroep zie L. Desmet, 'Les débuts de la télévision belge. «Voir loin avec les yeux d'ici ». Richesse et diversité des premiers JT', in : Médiatiques. Récit et société, 33, U CL, Louvain-la-Neuve 2003, p. I5-I8.

3 Analyse gebaseerd op vRT-Persdienst Televisie (2003). Programmabrochure 50 jaar televisie. Brussel: VRT en www.tvnieuws.be.

4 Het VRT-Jaarverslag 2004 is nog niet uitgegeven en de VRT-studiedienst kon deze cijfers nog niet vrijgeven.

5 Bron: vRT-studiedienst.

6 Op basis van de genre-indeling van сıм-Audiometrie en de programma-indeling van de VRT-productiediensten werden de verschillende programma's in één van deze categorieën ingedeeld. 
7 Bij wijze van voorbeeld: op I januari I970 haalde het programma WIJ HEREN VAN ZICHEM 2.960.000 kijkers, een kijkdichtheid van 74\% (www.een.be/televisies_master/vragen/e_vragen_ documentatie_kijkcijfers).

8 De meeste programma's bestonden uit meer dan één aflevering of uitzending. Op basis van programma-aankondigingen werd een ruwe berekening gemaakt van het aantal uitzendingen per programma(reeks). Dit resulteerde in ongeveer 480 uitzendingen entertainment (=75,6\%), , oo uitzendingen infotainment (=I5,8\%), 20 debatten \& studiogesprekken (=3,I\%) en 35 uitzendingen informatie \& documentaires $(=5,5 \%)$.

9 De opdeling naar prime time programma's werd in deze analyse overgenomen uit de aankondiging in de Programmabrochure 50 jaar televisie, namelijk die uitzendingen beginnend tussen I9:00 en 2I:00 uur.

IO A. Dhoest, Deverbeelde gemeenschap. 50 jaar Vlaamse tv-fictie en de constructie van een nationale identiteit, Leuven 2004. Zie ook Dhoests bijdrage in dit TMG-nummer.

II Ciм studies, Jaarverslag Ciм 2003, p. 59.

I2 J. Debackere, 'vRT sluit vijftigjarig jubileum tevreden af. Nostalgie doet het goed op TV', $D e$ Standaard, 7 oktober 2004 .

I3 Schrijven (e-mail) van W. Van Poucke (VAR - Vlaamse Audiovisuele Regie) aan J. Van Cauwenberge (VRT-Persdienst), L. Desmet, I5 april 2005.

I4 Er werd een gelijkaardig initiatief in I999 ondernomen waarbij de vRT elke dag in het journaal een nieuwsfeit uit de voorbije twintigste eeuw had uitgezonden. Van deze nieuwsitems bracht men drie videobanden op de markt [www.moviegids.be/index.cfm?id=906I4, I6 oktober 2000]. De verkoop van deze video's lag boven de Io०.০o० exemplaren [Schrijven (e-mail) van W. Van Poucke (VAR) aan J. Van Cauwenberge, L. Desmet, I5 april 2005].

I5 Enkele kijkcijfers feestweekend I-2 november 2003: WITTE RAVEN (I.203.000; 43,3\% marktaandeel); HET JOURNAAL (876.000; 4I\% marktaandeel); DE RODE LOPER (548.000; 33,I\% marktaandeel). Bron: cim Audimetrie en vRT-studiedienst. 